\title{
Especie nueva de Polylepis (Rosaceae) de la cordillera Vilcabamba (Cusco, Perú)
}

\author{
New species of Polylepis (Rosaceae) from Vilcabamba mountain range \\ (Cusco, Peru)
}

\author{
Wilfredo Mendoza ${ }^{1}$
}

Presentado: $17 / 05 / 2005$

Aceptado: $\quad 31 / 06 / 2005$

\section{Resumen}

Como parte del estudio sobre el género Polylepis en el Perú, se reconoce y describe una especie nueva que está restringida a la cordillera de Vilcabamba en el sur de Perú.

Palabras clave: Polylepis, Rosaceae, Andes, Vilcabamba, Perú.

\section{Abstract}

During the study of the genus Polylepis in Peru, one species restricted to the Vilcabamba mountain range, southern Peru was recognized as new and described herein.

Keywords: Polylepis, Rosaceae, Andes, Vilcabamba, Peru.

\section{Introducción}

El género Polylepis (Rosaceae) incluye alrededor de 20 especies restringidas a los bosques montanos y altoandinos de la cordillera de los Andes, distribuidas desde norte de Venezuela hasta norte de Chile y Argentina, con una población extratropical en el noroeste y centro de Argentina (Simpson, 1979; Cabido \& Acosta, 1985; Romoleroux, 1996; Kessler, 1995). Las especies de este género son principalmente árboles o arbustos, con troncos torcidos, corteza delgada y exfoliante (ritidoma); estípula connada y adnada al pecíolo. Hojas alternas, imparipinnadas. Inflorescencia simple, raramente ramificada. Flores generalmente con 4 brácteas simples; hipantio más o menos urceolado con espinas o alas; episépalo ausente; sépalos más o menos valvados persistentes; pétalos ausentes; estambres 6-36, anteras pubescentes; un carpelo; un óvulo pendular; estilo villoso o híspido en la base, estigma fimbriado. Fruto aquenio, con 1 semilla dentro del hipantio. Se-

(1) Museo de Historia Natural, Universidad Nacional Mayor de San Marcos. Av. Arenales 1256, Lima-14, Perú. Apartado postal: 14-0434, Lima 14, Perú.

Email Wilfredo Mendoza: wilfredomen@gmail.com millas más o menos fusiformes, con testa delgada o subcoreacea (Simpson, 1979; Romoleroux, 1996).

Para la flora peruana se han reportado de 10 a 12 especies (Macbride, 1938; Brako \& Zarucchi, 1993). Durante el desarrollo del estudio del género para la flora peruana, 15 especies hasta el momento han sido identificadas (Mendoza, datos inéditos).

La mayor concentración de especies se encuentra en los Andes del sur del Perú (Polylepis incana Kunth, P. pauta Hieron., P. subsericans J.F. Macbride, P.rugulosa Bitter, P. besseri Hieron., P. pepei B. B. Simpson, $P$. microphylla (Wedd.) Bitter, $P$. racemosa Ruiz \& Pavón, P. tarapacana Phil. y P. sericea Wedd.), posiblemente esto se deba a la gran heterogeneidad de hábitats que existe en esta región (Mendoza, 2000). Polylepis subsericans es la especie que alcanza altitudes de hasta $5100 \mathrm{~m}$ en la cordillera oriental de los Andes del sur del Perú (cadena del Vilcanota). En el presente trabajo se adiciona y se describe una especie nueva para esta zona, la cual está cercanamente emparentada a $P$. sericea. 


\section{Taxonomía}

Polylepis canoi W. Mendoza, sp. nov. (Figura 1a-g)

Tipo: Perú. Cusco. La Convención, cordillera del Vilcabamba. $30 \mathrm{~km}$ caminando de la hacienda Luisiana y del río Apurimac, $3400 \mathrm{~m}$, 12³0'S, 74³0'W, 17 Julio 1968 T.R. Dudley 11180 (Holotipo: MO; isotipo: NA, F).

\section{Descripción}

Differt Polylepis sericea vagina stipulare glabra, peciolis longioribus (2,5$2,9 \mathrm{~cm}$ vice 1,4-1,5 cm), foliolis majoribus (3-4 $\times 0,8-1,2 \mathrm{~cm}$ vice $1,4-3 \times 0,4-1 \mathrm{~cm})$, usque ad 4-jugis, hypanthio fructum parum rhomboideo spinis parvis planis praectito.

Árbol 4-5 m de alto; ritidomas de los troncos marrones rojizos, que se desprenden en pedazos largos. Vaina estipular con la superficie interior y exterior glabra, marrón rojiza. Hojas congestionadas en el extremo de las ramas; pecíolo 2,5-2,9 cm de longitud con pubescencia lanosa densa; hojas 8-9 x 5,5-7 cm, con (2) - 3 - (4) pares de foliolos, raquis con entrenudos lanosos, punto de unión de los foliolos con un anillo de pelos seríceos, mezclados con pequeñas glándulas de resina; foliolos lanceolados, 3-4 x 0,8-1,2 cm, base desigualmente cordada a ligeramente truncada, ápice ligeramente emarginado, margen entero o ligeramente aserrado, envés con pubescencia serícea densa blanca o marrón, haz con tricomas dispersos, principalmente en la depresión de la vena media. Racimo simple, 9 cm de longitud, con 6-7 flores; bráctea floral de 0,9-1 cm de longitud, seríceo. Flor de 0,9 $\mathrm{cm}$ de diámetro; hipantio tomentoso con pequeñas espinas planas; sépalos 4 ligeramente ovados a elípticos, abaxialente seríceos, adaxialmente glabros; antera $2 \mathrm{~mm}$ de longitud tomentosa; estilo fimbriado $4 \mathrm{~mm}$ de longitud, híspido en la base. Hipantio en fruto 0,50,6 × 0,3-0, $4 \mathrm{~cm}$ incluyendo espinas, ligeramente romboide, seríceos con espinas pequeñas planas.

\section{Ejemplares adicionales}

Perú. Cusco. La Convención, cordillera del Vilcabamba. $30 \mathrm{~km}$ caminando de la hacienda Luisiana y del río Apurimac, 3400 m, 19 July, 1968, T.R. Dudley 11221(USM, NA, F); Junín/Cusco. Satipo/La Convención, cordillera del Vilcabamba Río Ene slopes, ner summit of divide, $3350 \mathrm{~m}, 7$ June, 1997, B. Boyle et al. 4151(USM, F).

\section{Comentarios}

Polylepis canoi tiene la vaina estipular glabra, las hojas tienen el pecíolo $2,5-2,9 \mathrm{~cm}$ de longitud y los foliolos 3-4 x 0,8-1,2 cm y no tienen más de cuatro pares de foliolos (figura 1), en comparación $P$. sericea tiene la vaina estipular seríceo y las hojas tienen el pecíolo 0,4-1,5 cm de longitud y los foliolos 1,4-3 x $0,4-1 \mathrm{~cm}$ y puede tener hasta siete pares de foliolos, el hipantio del fruto es turbinado o fusiforme con espinas angostas largas; en $P$. canoi el hipantio del fruto es ligeramente romboide con espinas pequeñas planas.

La cordillera de Vicabamba ha sido poco explorada por los botánicos, por tal razón solamente tres ejemplares han sido colectados de esta especie nueva. Las dos colectas de Dudley fueron realizadas en 1968 y la última en 1997 durante la expedición organizada por el Programa de Evaluación Rápida (RAP) de Conservación Internacional (CI) y Conservación Internacional-Perú (CI-Perú).

Esta especie nueva hasta el momento se conoce sólo para la parte altoandina de la cordillera del Vilcabamba, donde posiblemente esté restringida su distribución lo que podría atribuirse al aislamiento en que se encuentran estos bosques de Polylepis. La cordillera del Vilcabamba en gran parte ha sido separada de los Andes centrales de Perú, conectándose solamente con una porción en el extremo sur; este aislamiento ha ocasionado un alto grado de endemismo tanto de flora como de fauna (Alonso et al., 2001). Esta particularidad se ve documentada por los resultados del RAP-CI donde sorprendentemente, se con- 


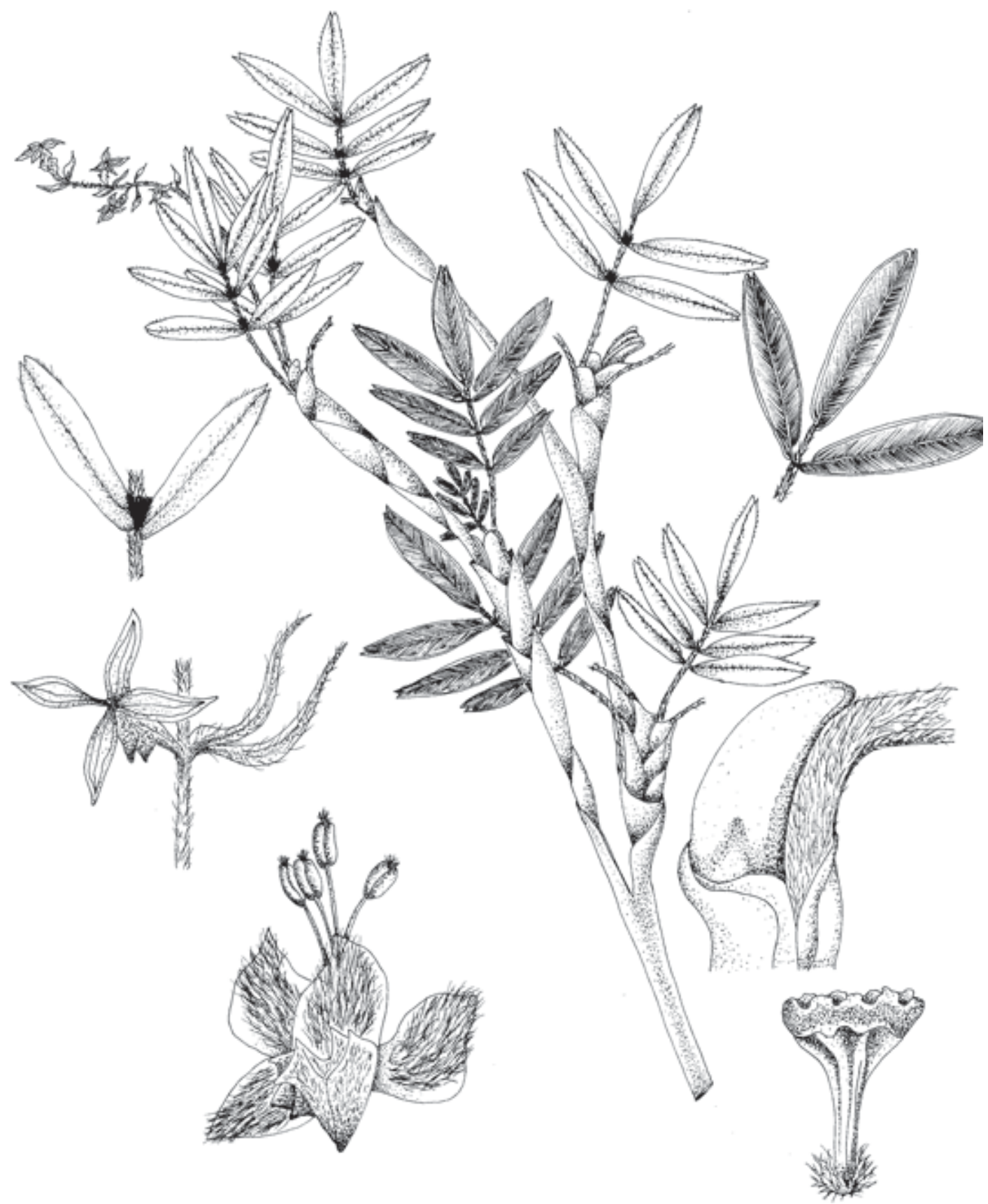

Figura 1. Polylepis canoi W. Mendoza, a) Rama con inflorescencia; b) Envés del foliolo; c) Haz del foliolo; d) Vaina estipular; e) fruto, f) flor y g) estilo y estigma. T.R. Dudley 11180 (MO). Escalas: a) $1 \mathrm{~cm}$, b) $1 \mathrm{~cm}$, c) $1 \mathrm{~cm}$, d) $2 \mathrm{~mm}$ e) $0,5 \mathrm{~mm}$, f) 0,5 $\mathrm{mm}$ y g) $4 \mathrm{~mm}$.

cluye que en los extensos bosques de Polylepis evaluados en esta cordillera, no se encontró ninguna de las especies de aves frecuentemente asociadas con Polylepis en otras regiones de los Andes (Alonso et al., 2001).
En la Cordillera del Vilcabamba se encuentran tres especies de Polylepis: P. canoi, P. pauta y $P$. sericea. Es preciso indicar que la especie nueva fue denominada como Polylepis sp1 por Boyle (2001) y que llega a formar grandes parches boscosos. 
Esta especie nueva es dedicada al botánico peruano Asunción Alipio Cano Echevarría, en reconocimiento a su labor científica, en particular en la parte altoandina del Perú.

\section{Agradecimientos}

Mi agradecimiento a los benefactores de la beca Christensen y en especial a Rodolfo Vásquez y Rocío Rojas del Missouri Botanical Garden por permitirme realizar una pasantía en St. Louis, a los curadores del Herbario San Marcos (USM), Missouri Botanical Garden (MO), Herbarium U.S. National Arboretum Washington D.C. (NA) y Field Museum of Natural History (F), en especial a Jim Solomom (MO), Robin Foster (F), Asunción Cano y José Roque (USM), a Alina Freire-Fierro, Blanca León, Henk van Der Werff, José Antonio Ochoa y Rosa Milagros Vento por sus comentarios y sugerencias sobre la descripción de esta nueva especie. Asimismo, agradezco a la Dra. Beryl B. Simpson por su acertada revisión del artículo y finalmente a Roosevelt García y Williams Farfán por la elaboración del dibujo de la Figura 1.

\section{Literatura citada}

Alonso L.E., A. Alonso, T.S. Schulenberg, F. Dallmeir, (eds.). 2001. Biological and Social Assessments on the Cordillera de Vilcabamba, Peru, Rap Working Papers, 12: 21-61.

Boyle B. 2001. Vegetation of two sites in the northern cordillera de Vilcabamba, Peru Pp. 69-79 in Alonso, L.E., Alonso, A., Schulenberg T.S., Dallmeir, F. (eds.). Biological and Social Assessments on the Cordillera de Vilcabamba, Peru, Rap Working Papers, 12: 69-79.

Brako L. \& J.L. Zarucchi. 1993. Catalogue of the Flowering Plants and Gymnosperms of Peru. Monographs in Systematic Botany. Missouri Botanical Garden, 45: 1003-1010.

Cabido M \& A. Acosta. 1985. Estudio fitosociológico en bosques de Polylepis australis Bitter: («Tabaquillo») en las sierras de Córdoba. Argentina. Documents phytosociologiques. N.S. Vol. IX, 365-400.

Kessler M. 1995. The genus Polylepis (Rosaceae) in Bolivia. Candollea, 50: 131-171.

Macbride J.F. 1938. Flora of Perú. Volumen XIII, Parte II: 1036-1119. Botanical Series. Field Museum Natural History.

Mendoza W. 2000. Diversidad de flora vascular asociada a los bosques de Polylepis (Rosaceae) en tres segmentos de la cordillera de los Andes del Perú. Universidad Nacional de San Antonio Abad del Cusco. Tesis de Licenciatura.

Simpson B. 1979. A revision of the genus Polylepis (Rosaceae: Sanguisorbeae). Smithsonian Contributions to Botany, 43:1-62.

Romoleroux. K. 1996. Rosaceae. Pp. 71-89 in Harling, G. \& L. Anderson (eds.) Flora of Ecuador 56. Göteborg University. 